OPEN ACCESS

Edited by:

Lisa Chiara Fellin,

University of Bergamo, Italy

Reviewed by:

Stella Guarnieri,

University of Bergamo, Italy

Nicole R. DeTore,

Massachusetts General Hospital,

United States

*Correspondence:

Xiaoling Lin

linxling3@mail.sysu.edu.cn

Specialty section:

This article was submitted to

Psychology for Clinical Settings,

a section of the journal

Frontiers in Psychology

Received: 02 November 2021 Accepted: 27 December 2021

Published: 28 January 2022

Citation:

Dou W, Yu X, Fang H, Lu D, Cai L, Zhu $C$, Zong $K$, Zheng $Y$ and Lin $X$ (2022) Family and Psychosocial Functioning in Bipolar Disorder:

The Mediating Effects of Social

Support, Resilience and Suicidal

Ideation. Front. Psychol. 12:807546.

doi: 10.3389/fpsyg.2021.807546

\section{Family and Psychosocial Functioning in Bipolar Disorder: The Mediating Effects of Social Support, Resilience and Suicidal Ideation}

\author{
Wenbo Dou ${ }^{1}$, Xueying Yư ${ }^{2}$, Hengying Fang ${ }^{2}$, Dali Lư ${ }^{3}$, Lirong Cai ${ }^{4}$, Caihong Zhu', \\ Kunlun Zong ${ }^{5}$, Yingjun Zheng ${ }^{5}$ and Xiaoling Lin ${ }^{1 *}$ \\ ${ }^{1}$ School of Nursing, Sun Yat-sen University, Guangzhou, China, ${ }^{2}$ Third Affiliated Hospital of Sun Yat-sen University, \\ Guangzhou, China, ${ }^{3}$ Xiamen Xianyue Hospital, Xiamen, China, ${ }^{4}$ Guangdong Provincial People's Hospital, Guangzhou, \\ China, ${ }^{5}$ Guangzhou Brain Hospital, Guangzhou Medical University, Guangzhou, China
}

Patients with bipolar disorder $(B D)$ may experience family dysfunction, which might result in worse psychosocial functioning through environmental and psychological factors. Research investigating the mediating role of social support, resilience and suicidal ideation on family and psychosocial functioning in $\mathrm{BD}$ is rare. The study aims to explore the predicting and mediating effects of social support, resilience and suicidal ideation on family and psychosocial functioning in BD patients. Two hundred forty-six patients with $\mathrm{BD}$ and sixty-nine healthy controls were recruited. The Family Assessment Device (FAD), Functioning Assessment Short Test (FAST), Social Support Rating Scale (SSRS), Connor-Davidson Resilience Scale (CD-RISC) and Beck Scale for Suicide Ideation $(B S /)$ were used to assess family functioning, psychosocial functioning, social support, resilience and suicidal ideation, respectively. Bipolar patients exhibited worse family and psychosocial functioning than healthy controls. Family functioning, social support, resilience and suicidal ideation significantly predict psychosocial functioning in the bipolar group. Social support, resilience and suicidal ideation indirectly mediate the effect of family functioning on psychosocial functioning in bipolar patients. Crosssectional design and mixed sample including acute and remitted stages. Treatments for patients with bipolar disorder should be combined with family strategies that are formulated to improve psychosocial functioning. An emphasis should be placed on enhancing social support and resilience while paying attention to suicidal ideation.

Keywords: bipolar disorder, family functioning, psychosocial functioning, social support, resilience, suicidal ideation

\section{INTRODUCTION}

Bipolar disorder (BD) is a lifelong refractory psychiatric mental illness that has a high episode frequency, comorbidity and poor functional outcomes (Du Rocher et al., 2008; Sole et al., 2018; Carvalho et al., 2020). Almost all patients with BD are challenged to maintain family relationships while managing severe psychosocial functioning. Impairments in family functioning are one of the most functional impairments in bipolar disorder, and poorer family functioning is associated with impaired psychosocial functioning (Du Rocher et al., 2008; MacPherson et al., 2018). Evidence 
has shown that family-based psychosocial interventions can reduce the number of hospital admissions and decrease the risk of relapse (West and Cosgrove, 2019). Research on family and psychosocial functioning in serious mental illness has gained increasing interest in recent years.

Bipolar disorder patients and their family members have been characterized by high levels of expressed emotion, the absence of family cohesion and family adaptability and significant inadequate family interpersonal relationships (West and Cosgrove, 2019; Zhang et al., 2019). All these features of bipolar families result in lower perceived family and social support from surroundings and are associated with difficulties establishing intimate relationships. Family functioning as a risk or a protective factor plays a critical role throughout the lives of BD patients (Chang et al., 2001). For instance, lower family cohesion and adaptability and higher conflict could predict poor mood symptoms in patients with $\mathrm{BD}$ (Sullivan et al., 2012). However, family-focused therapy to promote emotional stability improves family functioning by enhancing the problem solving and communication abilities of BD patients (Miklowitz and Chung, 2016). Patients with bipolar disorder always experience impairment of psychosocial functioning during observation of family relationships and life satisfaction (Perlis et al., 2009).

Notably, family variables have been demonstrated to serve as moderators and mediators of psychosocial outcomes in BD patients (Sullivan et al., 2012; MacPherson et al., 2018). Nevertheless, Stapp et al. (2019) demonstrated that parental BD predicts high family conflict and poor family environment, and mothers with $\mathrm{BD}$ require psychosocial support to address family functioning. Parental psychosocial functioning mediates the correlation between clinical symptoms and family dysfunction (Shalev et al., 2019). Improvement in symptomatic remission does not mean the recovery of psychosocial functioning (Karow et al., 2012); environmental factors, such as family functioning and social reintegration, cannot be ignored (Sullivan et al., 2012; Guerrero-Jimenez et al., 2021). The relations between family and psychosocial functioning are likely bidirectional. Psychosocial functioning interventions are beneficial in improving family conflict, enhancing cohesion and moderating family adaptability in bipolar disorder patients (O’Donnell et al., 2020). However, research analyzing the correlations between family and psychosocial functioning in patients with bipolar disorder is rare. Previous research has always paid exclusion attention to pharmacotherapy in patient illness episodes without consideration of their familial circumstances and the adaptive capacity of considerable adversity (Miklowitz and Chung, 2016). Thus, the correlation between family and psychosocial functioning warrants further investigation.

The current findings by Dunne et al. (2019) suggest that the support of family, friends and partners may contribute to personal recovery and psychosocial functioning in $\mathrm{BD}$ patients and help individuals build resilience and cope with adverse environments effectively (Zhou et al., 2019). Structural equation modeling illustrated that social support has an irreplaceable effect between clinical symptoms and household poverty, and better social support indicate higher household income and lower caregiving burden (Yu et al., 2020). Dou et al. (under review) reported that higher social support predicted better family and psychosocial functioning, and social support also played a moderating role in the relationship between family functioning and psychosocial functioning in $\mathrm{BD}$ patients. A strong relationship was noted between impaired family functioning and inadequate social support in depression patients (Wang and Zhao, 2012). Additionally, social support had a mediating and moderating effect between childhood abuse and subsequent outcomes (Sperry and Widom, 2013). However, the relationship among family functioning, social support and psychosocial functioning in patients with $\mathrm{BD}$ also requires further exploration.

Resilience refers to the approach to positive adaptation when confronting stress, trauma, family tragedy or significant adversity that would be expected to cause acute sequelae (Cicchetti, 2010). Individuals and families are able to respond successfully to disadvantages and persistent challenges and to recover and expand through resilience, which was proposed in the family resilience framework (Walsh, 2003). The present study exemplified that better performance in family functioning indicated greater resilience and predicted better mental health in hemodialysis patients (Kukihara et al., 2020). Resilience and life satisfaction are partially mediated by perceived social support in substance use disorder (Yang et al., 2020). Higher resilience is associated with better psychosocial functioning, which has been investigated in clinically stable BD outpatients (Mizuno et al., 2016). Hence, the finding explored by Kim et al. (2013) suggest that a significant relationship exists between impaired psychosocial functioning and a lower level of resilience in individuals at ultrahigh risk for psychosis. The level of resilience in $\mathrm{BD}$ patients is lower than that in healthy controls, even in the euthymic period (Lee et al., 2017). However, few studies have focused on examining the relationship among resilience, family functioning and psychosocial functioning in patients with BD.

Furthermore, the role of suicidal ideation between family and psychosocial functioning in BD has been poorly investigated. Approximately $59 \%$ of patients with $\mathrm{BD}$ have suicidal ideation, and this proportion is 20-30 times that of the general population (Abreu et al., 2009; Pompili et al., 2013). Excessive expressed emotion, reduced family cohesion and increased family conflict are associated with increased suicidal ideation in patients with BD (Weinstein et al., 2015; Berutti et al., 2016). Young adults with enduring suicidal ideation often have a heightened risk of psychosocial dysfunction (Steinhausen and Metzke, 2004). Our previous research failed to explore the correlation between suicidal ideation and psychosocial functioning (Luo et al., 2020). It is necessary to further clarify how suicidal ideation impacts family functioning and psychosocial functioning, which will contribute to accurate intervention measures in family and psychosocial functioning and reduce suicidal attempts in $\mathrm{BD}$ patients.

To the best of our knowledge, this is the first study to explore the mediating effects of social support, resilience and suicidal ideation on the relationship between family and psychosocial functioning in $\mathrm{BD}$ patients. The study aims (i) to compare 
family functioning, psychosocial functioning, social support, resilience and suicidal ideation between bipolar patients and healthy controls; (ii) to evaluate the associations among family functioning, social support, resilience, suicidal ideation and psychosocial functioning in BD patients; (iii) to identify potential predictors of psychosocial functioning in bipolar patients; and (iv) to investigate the mediating effects of social support, resilience and suicidal ideation on family and psychosocial functioning in bipolar patients.

\section{MATERIALS AND METHODS}

\section{Participants}

A cross-sectional design was used in the present study. Patients enrolled in this study were approved by the psychiatric inpatient department and outpatient department of Xiamen Xianyue Hospital, the Affiliated Brain Hospital of Guangzhou Medical University and the Third Affiliated Hospital of Sun Yat-sen University, Xiamen and Guangzhou Cities, China between April 2019 to December 2019 and September 2020 to April 2021. Two psychiatrists are responsible for the diagnosis and clinical states, using the Structured Clinical Interview for DSM- $V$ Axis I Disorders, Clinical version (SCID-CV) in conjunction with the Young Mania Rating Scale (YMRS) (Young et al., 1978) and the 17-item Hamilton Depression Rating Scale (HDRS17) (Hamilton, 1960). Patients' exclusion criteria included current or lifetime diagnosis of active psychotic symptoms or intellectual disability (Wechsler Adult Intelligence Scale score $<70$ ); dementia, substance or alcohol abuse within one year; head injury; electroconvulsive therapy (ECT) in the last year; engagement in any structured psychological intervention that might affect cognitive functioning within the last 2 years; and other physical or neurological illness or an unstable medical disease condition. Finally, a total of 246 patients with a mean age of $28.37(S D=11.92)$ years old, including manic and hypomanic as well as depressed and euthymic states, were included in this research. No patient was drug-free, and valproate, lithium and antipsychotics (including quetiapine, olanzapine and risperidone, etc.) were the three most frequently used drugs (see Table 1).

Healthy individuals were recruited form two communities in Guangzhou, China, using a convenience sampling method. The healthy group was matched to the age and gender of patients of bipolar disorder. Finally, sixty-nine healthy controls (HCs) with a mean age of $31.3(S D=9.29)$ years old, had a negative history of psychiatric disease both personally and in their firstdegree relatives, and the participants failed to reach the criteria of any axis mental disorder evaluated by the DSM-V Structured Clinical Interview. Additionally, participants who were pregnant or lactating were excluded. All participants communicated using Chinese and completed all assessments independently. Written informed consent was provided by each participant following a detailed explanation of the procedures. Ethical authorisation for the article, which has been obtained ethics committee approval by Sun Yat-sen University.
TABLE 1 | Demographic, clinical and pharmacological characteristics in patients with bipolar disorder and healthy controls.

\begin{tabular}{|c|c|c|c|c|c|c|}
\hline \multirow[t]{2}{*}{ Variables } & \multicolumn{2}{|c|}{$\begin{array}{l}\text { Patients with } \\
\text { bipolar disorder } \\
\text { (n=246) }\end{array}$} & \multicolumn{2}{|c|}{$\begin{array}{l}\text { Healthy controls } \\
\qquad(n=69)\end{array}$} & \multicolumn{2}{|c|}{ ANOVA } \\
\hline & Mean & $S D$ & Mean & $S D$ & $\boldsymbol{F}$ & $p$ \\
\hline Age (years) & 28.37 & 11.92 & 31.3 & 9.29 & 11.048 & 0.059 \\
\hline $\begin{array}{l}\text { Body mass index, } \\
\left(\mathrm{BMI}, \mathrm{kg} / \mathrm{m}^{2}\right)\end{array}$ & 22.43 & 4.11 & 22.69 & 4.54 & 0.036 & 0.637 \\
\hline $\begin{array}{l}\text { Waist hip ratio } \\
(\mathrm{WHR})\end{array}$ & 0.86 & 0.09 & 0.83 & 0.07 & 13.340 & $0.035^{\star}$ \\
\hline HDRS-17 score & 9.57 & 7.68 & 2.00 & 2.31 & 58.191 & $<0.001^{\star *}$ \\
\hline YMRS score & 6.68 & 5.73 & 1.04 & 2.50 & 47.491 & $<0.001^{\star \star}$ \\
\hline $\begin{array}{l}\text { Age at onset } \\
\text { (years) }\end{array}$ & 21.22 & 8.42 & - & - & - & - \\
\hline $\begin{array}{l}\text { Age at treatment } \\
\text { (years) }\end{array}$ & 22.89 & 8.40 & - & - & - & - \\
\hline \multirow{2}{*}{$\begin{array}{l}\text { Duration of illness } \\
\text { (years) }\end{array}$} & 7.56 & 8.01 & - & - & - & - \\
\hline & $N$ & $\%$ & $N$ & $\%$ & $\chi^{2} / t$ & $p$ \\
\hline $\begin{array}{l}\text { Gender } \\
\text { (Male/Female) }\end{array}$ & $90 / 156$ & $36.6 / 63.4$ & $27 / 42$ & $39.1 / 60.9$ & 0.150 & 0.699 \\
\hline $\begin{array}{l}\text { Race (Han/Others } \\
\text { nations) }\end{array}$ & $242 / 4$ & $98.4 / 1.6$ & $67 / 2$ & $97.1 / 2.9$ & 0.467 & 0.494 \\
\hline $\begin{array}{l}\text { Marital status } \\
\text { (single/non-single) }\end{array}$ & $163 / 83$ & $66.3 / 33.7$ & $42 / 27$ & $60.9 / 39.1$ & 0.689 & 0.407 \\
\hline $\begin{array}{l}\text { Occupational } \\
\text { status (yes/no) }\end{array}$ & $50 / 196$ & $20.3 / 79.7$ & $56 / 13$ & $81.2 / 18.8$ & 89.318 & $<0.001^{\star *}$ \\
\hline Educational level & & & & & 34.766 & $<0.001^{\star *}$ \\
\hline$\leq$ Primary school & 72 & 29.3 & 14 & 20.3 & & \\
\hline Middle school & 106 & 43.1 & 10 & 14.5 & & \\
\hline$\geq$ College & 68 & 27.6 & 45 & 65.2 & & \\
\hline $\begin{array}{l}\text { Family psychotic } \\
\text { history (yes/no) }\end{array}$ & $53 / 193$ & $21.5 / 78.5$ & - & - & - & - \\
\hline $\begin{array}{l}\text { Past psychotic } \\
\text { history (yes/no) }\end{array}$ & $32 / 214$ & $13.0 / 87.0$ & - & - & - & - \\
\hline \multicolumn{7}{|l|}{ Medications } \\
\hline Lithium & 88 & 35.8 & - & - & - & - \\
\hline Valproate & 106 & 43.1 & - & - & - & - \\
\hline Lamotrigine & 15 & 6.1 & - & - & - & - \\
\hline Oxcarbazapine & 33 & 13.4 & - & - & - & - \\
\hline Antipsychotics & 203 & 82.5 & - & - & - & - \\
\hline Antidepressants & 15 & 6.1 & - & - & - & - \\
\hline Benzodiazapines & 88 & 35.8 & - & - & - & - \\
\hline Benzhexol & 24 & 9.8 & - & - & - & - \\
\hline Propranolol & 17 & 6.9 & - & - & - & - \\
\hline Others & 50 & 20.3 & - & - & - & - \\
\hline
\end{tabular}

ANOVA, Analysis of Variance; SD, Standard deviation; HDRS-17, The 17-item Hamilton Depression Rating Scale; YMRS, The Young Mania Rating Scale; Others, Coenzyme Q10 Capsules; Bisoprolol Fumarate; Hydrotalcite; Omeprazole; Metoprolol; Bisacodyl; Polyene Phosphatidylcholine Capsules; Metformin. ${ }^{*} p<0.05,{ }^{* *} p<0.01$.

\section{Assessments \\ Demographic and Clinical Assessments}

Demographic, clinical and pharmacological data were collected via structured interviews with the patients and/or their guardians 
and clinical records (see Table 1). The measurements of depression and manic symptoms were assessed using the HDRS17 and YMRS, respectively. A psychiatrist was responsible for measuring the psychotic symptoms of patients who were blinded to the clinical and psychosocial evaluation results.

\section{Family Functioning}

Family functioning was assessed using the Family Assessment Device (FAD) (Epstein et al., 1983). The FAD is a 60 -item screening self-rating questionnaire used to measure possible problems in the familial system. Each item uses a 4-level rating: range from 1 to 4 point. Higher scores on the total scale or its subscales indicated worse family functioning.

\section{Psychosocial Functioning}

The Functioning Assessment Short Test (FAST) was used to measure psychosocial functioning based on 24 items (Bonnin et al., 2016). Each item of the FAST is answered on a four-point Likert-type score ranging from 0 to 3 , and the total score ranges from 0 to 72 with higher scores indicating worse psychosocial functioning (Zhang et al., 2018).

\section{Social Support}

The Social Support Rating Scale (SSRS) was used to measure the social support of patients with bipolar disorder. The SSRS is consisting of 10 items measuring the perception of subjects from subjective and objective support, and support utilization. The total score ranges from 12 to 66 with higher scores indicating better social support (Wang et al., 2015).

\section{Resilience}

Resilience was assessed using the Connor-Davidson Resilience Scale (CD-RISC) (Connor and Davidson, 2003). The self-report questionnaire measures the degree of resilience in patients bipolar disorder, which the authors defined as "a positive individual characteristic that acquires the meaningful of life." The Chinese version of the CD-RISC comprises 25 items. Each item uses a 5-level rating, ranging from 0 (never) to 4 (always). The total score ranges from 0 to 100 , and a greater score indicates increased quality of resilience (Xian-Yun et al., 2010).

\section{Suicidal Ideation}

The Beck Scale for Suicide Ideation (BSI) (Beck et al., 1979) was used to measure the level of suicidal ideation. The BSI consisted of 19 items and was divided into two parts: suicidal ideation and suicidal behavior. Each item uses a 3-level rating from 0 to 2 , and higher scores indicated stronger suicidal ideation. The first 5 items in the BSI were used to assess suicidal ideation among participants.

\section{Statistical Analysis}

Analyses were conducted using Statistical Package for the Social Sciences (SPSS) version 25.0 and IBM AMOS version 23.0 (SPSS Inc., Chicago, IL, United States). Means and standard deviations (SD) were used to describe descriptive variables, and numbers $(n)$ and percentages (\%) were used for categorical variables. The normality of all data were test by the Shapiro-Wilk test. The mean differences in the demographic and clinical variables in the patient and HC groups were compared using the chi-square $\left(\chi^{2}\right)$, one-way analysis of variance (ANOVA) followed by Bonferroni post-hoc tests or Mann-Whitney $U$ tests. Partial correlation analyses were used to quantify potential bivariate associations among the FAD, SSRS, CD-RISC, BSI and FAST after controlling for HDRS-17 and YMRS scores, which are factors reported in our previous studies that potentially influence cognitive and psychosocial functioning (Lin et al., 2020). Several hierarchical regression analysis models were used to investigate those variables that could be predictors of psychosocial functioning. Total FAST scores and each dimension were introduced as the dependent variable in each model. The HDRS-17 and YMRS scores were entered in the first block as independent variables. The scores of the subscales of the FAD and SSRS and the BSI and CD-RISC scores were introduced in the second block as independent variables using a stepwise method. All the values of variance inflation factor $(V I F)<10$ and the values of tolerance $>0.1$ were considered adequate for the tests for multicollinearity. All statistics were tested using two-tailed comparisons and the 0.05 significance criterion.

The mediating effects in the hypothesis were examined using a structural equation model (SEM) constructed by AMOS 23.0. According to our previous study, family functioning could predict psychosocial functioning in BD patients, and social support had predicting and moderating effects on family functioning and psychosocial functioning (Dou et al. under review). Resilience mediates family adaptability and wellbeing and predicts psychosocial functioning, and this effect is strengthened by the inclusion of social support (Kukihara et al., 2020; Wang et al., 2021). Furthermore, the impairment of family functioning may lead to suicidal ideation, thereby impairing the psychosocial functioning of $\mathrm{BD}$ patients (Goldstein et al., 2009; Berutti et al., 2016). The original model is shown in Figure 1A.

Maximum likelihood estimation, including Chi-square/degree of freedom $\left(\chi^{2} / d f\right)$, incremental fit index (IFI), comparative fix index $(C F I)$ and root mean square error of approximation (RMSEA), was used to test the satisfaction of each model. The model was deemed to have an acceptable fit when every path coefficients was significant ( $p$-values $<0.05$ ); Chi-square/degree of freedom $\left(\chi^{2} / d f\right)$ was less than 2 ; root mean square error of approximation (RMSEA) was less than 0.08; and goodness-of-fit index $(G F I)$, comparative fit index $(C F I)$, normed fit index (NFI) and the Tacker-Lewis Index (TLI) were greater than or equal to 0.90 (McDonald and Ho, 2002). The standard estimate for the effects (direct, indirect, and total) was used to determine the connection between the observed and latent variables. Materials and analysis code for this study are available by emailing the corresponding author.

\section{RESULTS}

\section{Descriptive Analyses}

The BD and HC groups did not show significant differences in most of the demographic variables, except for occupational status, educational level and WHR $(p<0.05$, see Table 1). As 

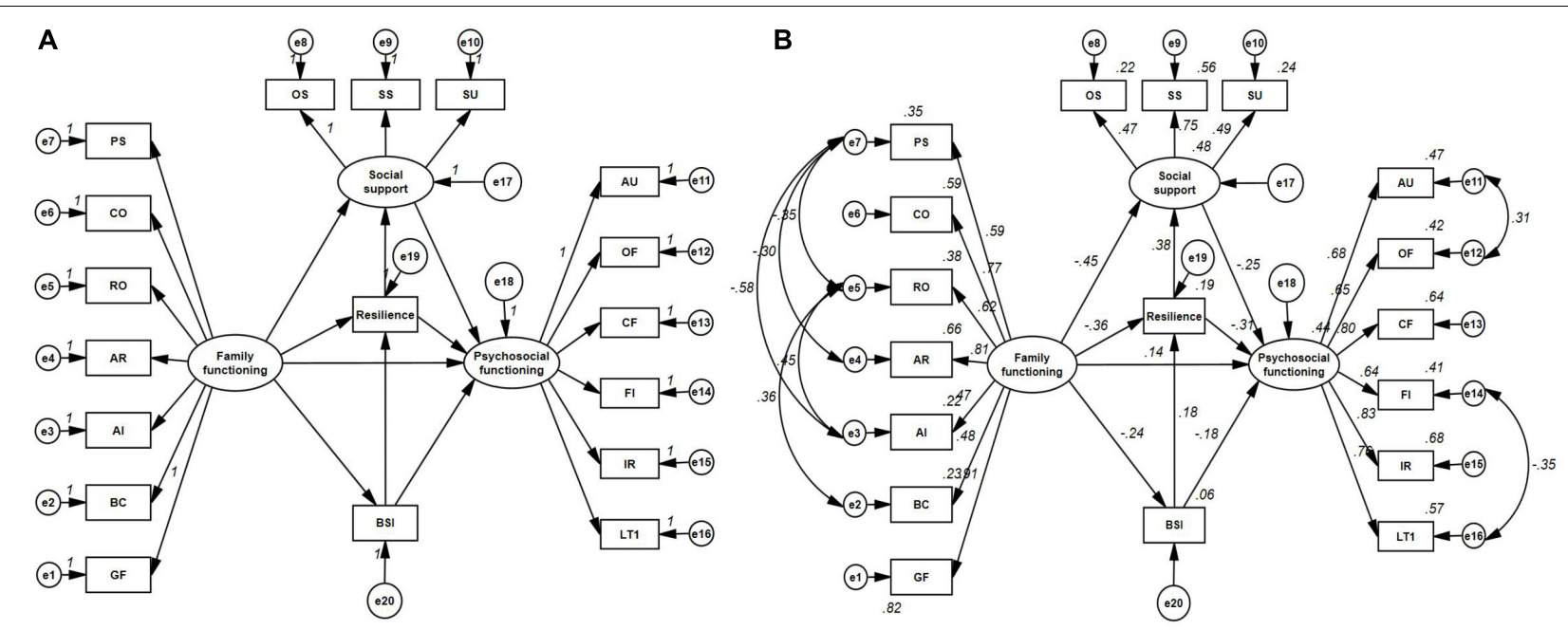

FIGURE 1 | The original model (A) and final model (B). PS, Problem Solving; CO, Communication; RO, Roles; AR, Affective Responsiveness; Al, Affective Involvement; BC, Behavior Control; GF, General Functioning; OS, Objective Support; SS, Subjective Support; SU, Support Utilization; AU, Autonomy; OF, Occupational Functioning; CF, Cognitive Functioning; FI, Financial Issue; IR, Interpersonal Relationships; LT, Leisure Time; BSI, Beck Scale for Suicide Ideation.

expected, significant differences $(p<0.001)$ in the HDRS-17 and YMRS scores were noted the BD and HC groups.

As shown in Table 2, patients with BD rated significantly worse in family functioning and all psychosocial functioning areas than healthy individuals (all $p$-values $<0.05$ ), except for behavior control of the FAD $(p=0.107)$. For social support, significant differences in the total score of the SSRS $(p=0.018)$ and the subscale of subjective support $(p=0.003)$ were noted between the $\mathrm{BD}$ and $\mathrm{HC}$ groups, whereas no differences were observed in the subscales of objective support and support utilization between these two groups (all $p$-values >0.05). Furthermore, the BSI and CD-RISC scores in BD patients were lower than those in healthy individuals (all $p$-values $<0.001$ ).

\section{Correlational Analyses}

As shown in Table 3, the FAD total score was positively associated with the total and subscale scores of the FAST ( $r$ range from 0.16 to 0.35 , all $p$-values $<0.05$ ), whereas the FAST total score was positively correlated with the total and subscale scores of the FAD ( $r$ range from 0.13 to 0.30 , all $p$-values $<0.05$ ) with the exception of affective involvement $(r=0.09, p=0.16)$. In addition, significantly negative correlations were noted between the FAD and the SSRS, CD-RISC and BSI scores ( $r$ range from -0.15 to -0.42 , all $p$-values $<0.05)$ in patients with bipolar disorder. In addition, the FAST scores were negatively related to the SSRS, CD-RISC and BSI scores ( $r$ range from -0.15 to -0.46 , all $p$-values $<0.05)$ in the bipolar group. Furthermore, the SSRS was positively correlated with the CD-RISC and BSI scores $(r=0.39$, $p<0.001 ; r=0.15, p=0.02$; respectively), and the CD-RISC was also significantly associated with the BSI $(r=0.21, p=0.001)$ in patients with bipolar disorder.

\section{Hierarchical Regression Analyses}

Table 4 demonstrates that resilience had a predictive effect on the total and subscale scores of the FAST $(\beta$ ranging from -0.171 to -0.393 , all $p$-values $<0.05)$. Hierarchical regression analysis revealed that the significant predictors of the total FAST score included the HDRS-17 score $(\beta=0.216, p=0.001)$, the FAD score $(\beta=0.139, p=0.021)$, the CD-RISC score $(\beta=-0.393, p<0.001)$ and the BSI score $(\beta=-0.131, p=0.034)$, which explained $36.7 \%$ of the variance $\left(R^{2}=0.367, F=20.701, p=0.034\right)$. The HDRS-17 also predicted cognitive functioning $(\beta=0.198$, $p=0.005)$, financial issues $(\beta=0.201, p=0.009)$ and interpersonal relationships $(\beta=0.268, p<0.001)$.

The FAD predicted the dimensions of financial issues $(\beta=0.158, p=0.022)$ and interpersonal relationships $(\beta=0.142$, $p=0.023)$, and interpersonal relationships $(\beta=-0.197, p=0.003)$ and leisure time $(\beta=-0.154, p=0.029)$ were predicted by the SSRS. The significant predictor of the total FAST score, occupational functioning, cognitive functioning and leisure time was BSI ( $\beta$ ranging from -0.131 to -0.220 , all $p$-values $<0.05$ ). Interestingly, age $(\beta=-0.199, p=0.003)$ was predictive of occupational functioning, and financial issues were predicted by gender $(\beta=-0.163, p=0.012)$.

\section{Mediation Model}

In the original mediation model (see Figure 1A), the SSRS, CD-RISC and BSI scores were included as mediators of the relationship between the FAD and FAST scores. The final model demonstrated acceptable fit: GFI $=0.916$, NFI $=0.901$, $\mathrm{TLI}=0.944$, CFI $=0.956$, RMSEA $=0.054$. In addition, the Chisquare test $\left(\chi^{2}=207.259, p<0.001\right)$ and Chi-square/degree of freedom $\left(\chi^{2} / d f=1.713\right)$ were statistically significant after residuals correction. All beta values are standardized (see Figure 1B).

As presented in the final models (Figure 1B and Table 5), the direct effect between family functioning and psychosocial functioning was 0.137 after correction. The indirect effect through social support, resilience and suicidal ideation was calculated as follows: 
TABLE 2 | Comparisons on the family functioning, psychosocial functioning, social support, resilience and suicidal ideation between patients with bipolar disorder and healthy controls.

\begin{tabular}{|c|c|c|c|c|c|c|}
\hline \multirow[t]{2}{*}{ Variables } & \multicolumn{2}{|c|}{$\begin{array}{l}\text { Patients with } \\
\text { bipolar disorder } \\
\text { (n=246) }\end{array}$} & \multicolumn{2}{|c|}{$\begin{array}{l}\text { Healthy controls } \\
\qquad(n=69)\end{array}$} & \multicolumn{2}{|c|}{ ANOVA } \\
\hline & Mean & $S D$ & Mean & $S D$ & $\boldsymbol{F}$ & $p$ \\
\hline \multicolumn{7}{|l|}{ The FAD" } \\
\hline $\begin{array}{l}\text { Total score of } \\
\text { the FAD }\end{array}$ & 142.91 & 18.87 & 130.99 & 20.03 & 1.045 & $<0.001^{\star \star}$ \\
\hline Problem solving & 13.19 & 3.30 & 11.83 & 2.72 & 3.048 & $0.002^{* *}$ \\
\hline Communication & 21.83 & 4.02 & 19.62 & 4.16 & 0.780 & $<0.001^{\star \star}$ \\
\hline Roles & 25.90 & 4.19 & 24.39 & 4.50 & 0.462 & $0.010^{\star}$ \\
\hline $\begin{array}{l}\text { Affective } \\
\text { responsiveness }\end{array}$ & 14.96 & 2.98 & 13.88 & 3.07 & 0.497 & $0.007^{\star \star}$ \\
\hline $\begin{array}{l}\text { Affective } \\
\text { involvement }\end{array}$ & 17.57 & 3.29 & 16.46 & 2.44 & 2.447 & $0.005^{\star \star}$ \\
\hline Behavior control & 21.55 & 3.19 & 20.86 & 2.98 & 2.309 & 0.107 \\
\hline $\begin{array}{l}\text { General } \\
\text { functioning }\end{array}$ & 27.92 & 5.42 & 24.12 & 5.40 & 0.003 & $<0.001^{\star \star}$ \\
\hline \multicolumn{7}{|l|}{ The FAST" } \\
\hline $\begin{array}{l}\text { Total score of } \\
\text { FAST }\end{array}$ & 16.52 & 14.43 & 7.75 & 8.69 & 18.082 & $<0.001^{\star \star}$ \\
\hline Autonomy & 2.40 & 2.46 & 1.42 & 1.71 & 12.839 & $<0.001^{\star \star}$ \\
\hline $\begin{array}{l}\text { Occupational } \\
\text { functioning }\end{array}$ & 3.88 & 4.39 & 1.57 & 2.83 & 30.312 & $<0.001^{\star \star}$ \\
\hline $\begin{array}{l}\text { Cognitive } \\
\text { functioning }\end{array}$ & 3.35 & 3.63 & 1.64 & 2.28 & 17.186 & $<0.001^{\star \star}$ \\
\hline Financial issue & 1.45 & 1.78 & 0.59 & 1.18 & 28.464 & $<0.001^{\star \star}$ \\
\hline $\begin{array}{l}\text { Interpersonal } \\
\text { relationships }\end{array}$ & 4.15 & 4.21 & 1.84 & 2.70 & 14.065 & $<0.001^{\star \star}$ \\
\hline Leisure time & 1.33 & 1.63 & 0.72 & 1.10 & 19.595 & $<0.001^{\star \star}$ \\
\hline \multicolumn{7}{|l|}{ The SSRS $\#$} \\
\hline $\begin{array}{l}\text { Total score of } \\
\text { SSRS }\end{array}$ & 34.72 & 9.29 & 37.65 & 8.01 & 2.781 & $0.018^{\star}$ \\
\hline $\begin{array}{l}\text { Objective } \\
\text { support }\end{array}$ & 8.31 & 3.88 & 8.49 & 2.85 & 2.019 & 0.716 \\
\hline $\begin{array}{l}\text { Subjective } \\
\text { support }\end{array}$ & 19.24 & 5.88 & 21.57 & 5.42 & 0.881 & $0.003^{\star \star}$ \\
\hline $\begin{array}{l}\text { Support } \\
\text { utilization }\end{array}$ & 7.18 & 2.36 & 7.59 & 1.96 & 2.079 & 0.179 \\
\hline The CD-RISC\# & 55.61 & 23.13 & 67.87 & 17.91 & 5.319 & $<0.001^{\star \star}$ \\
\hline The BSI ${ }^{\#}$ & 6.25 & 5.54 & 1.93 & 2.07 & 9.996 & $<0.001^{\star *}$ \\
\hline
\end{tabular}

ANOVA, Analysis of Variance; SD, Standard deviation; FAD, Family Assessment Device; FAST, Functioning Assessment Short Test; SSRS, Social Support Rating Scale; CD-RISC, Connor-Davidson Resilience Scale; BSI, Beck Scale for Suicide Ideation.

\#Higher scores of the FAD, FAST, and BSI scales indicate worse family and psychosocial functioning, and stronger suicidal ideation, respectively.

\#Higher scores of the SSRS and CD-RISC indicate better social support and resilience, respectively.

${ }^{*} p<0.05 .{ }^{* *} p<0.01$.

Path 1. Family functioning $\rightarrow$ social support $\rightarrow$ psychosocial functioning

$$
\beta=-0.454 \times-0.250=0.114
$$

Path 2. Family functioning $\rightarrow$ resilience $\rightarrow$ psychosocial functioning

$$
\beta=-0.359 \times-0.314=0.113
$$

Path 3. Family functioning $\rightarrow$ suicidal ideation $\rightarrow$ psychosocial functioning

$$
\beta=-0.236 \times-0.185=0.044
$$

Path 4 . Family functioning $\rightarrow$ resilience $\rightarrow$ social support $\rightarrow$ psychosocial functioning

Combined $\beta=-0.359 \times 0.375 \times-0.250=0.034$

Path 5. Family functioning $\rightarrow$ suicidal ideation $\rightarrow$ resilience $\rightarrow$ psychosocial functioning

Combined $\beta=-0.236 \times 0.177 \times-0.314=0.013$

Path 6. Family functioning $\rightarrow$ suicidal ideation $\rightarrow$ resilience $\rightarrow$ social support $\rightarrow$ psychosocial functioning Combined $\beta=-0.236 \times 0.177 \times 0.375 \times-0.314=0.005$

The final model demonstrated that psychosocial functioning was predicted indirectly $(\beta=0.323)$ by family functioning through social support $(\beta=0.114$; combined $\beta=0.034)$, resilience ( $\beta=0.113$; combined $\beta=0.013)$ and suicidal ideation $(\beta=0.044$; combined $\beta=0.005$ ), explaining a total of $43.8 \%$ of the variance in psychosocial functioning $\left(R^{2}=0.438\right)$.

\section{DISCUSSION}

To the best of our knowledge, this is the first study to investigate the mediating role of social support, resilience and suicidal ideation on family and psychosocial functioning in BD patients using a structural equation model. The results demonstrated that bipolar patients rated worse family and psychosocial functioning than healthy population. Furthermore, family functioning, social support, resilience and suicidal ideation could significantly predict psychosocial functioning in bipolar patients. Notably, social support, resilience and suicidal ideation could indirectly mediate the effect of family functioning on psychosocial functioning in bipolar patients.

Patients with BD had significant family and psychosocial dysfunction compared to healthy controls, which was in line with previous studies (MacPherson et al., 2018; Shalev et al., 2019). Findings add to the research on family factors and worse courses in patients with $\mathrm{BD}$ and indicate that family and psychosocial functioning are obviously dysfunctional, which demands consideration in implementing interventions (MacPherson et al., 2018; Luo et al., 2020). Interestingly, no difference in behavior control was noted between BD patients and healthy controls. This finding is inconsistent with earlier research (Keenan-Miller et al., 2012; MacPherson et al., 2018), which may be related to the different participants and measurements. Keenan-Miller et al. (2012) assessed family functioning and social impairment based on The Family Adaptability and Cohesion Evaluation Scale II (FACES-II) and The Conflict Behavior Questionnaire $(C B Q)$. Behavior control refers to the way family members maintain expectations for each other (MacPherson et al., 2018). It is not surprising that children and adolescents were given more care and expectations than adults in families and that worse behavior control may increase the likelihood of family aggression by children with affective mental disorders (KeenanMiller et al., 2012; Shalev et al., 2019). Existing family therapies 
TABLE 3 | The partial correlations ${ }^{\#}$ among family functioning, psychosocial functioning, social support, resilience and suicidal ideation in patients with bipolar disorder.

\begin{tabular}{|c|c|c|c|c|c|c|c|c|c|c|c|c|c|c|c|c|c|c|c|c|c|}
\hline \multirow[t]{2}{*}{ Variables } & \multicolumn{8}{|c|}{ FAD } & \multicolumn{7}{|c|}{ FAST } & \multicolumn{4}{|c|}{ SSRS } & \multirow{2}{*}{$\frac{\text { CD-RISC }}{(20)}$} & \multirow{2}{*}{$\frac{B S I}{(21)}$} \\
\hline & (1) & (2) & (3) & (4) & (5) & (6) & (7) & (8) & (9) & (10) & (11) & (12) & (13) & (14) & (15) & (16) & (17) & (18) & (19) & & \\
\hline (1) FAD & 1 & & & & & & & & & & & & & & & & & & & & \\
\hline (2) $P^{1}{ }^{1}$ & $0.45^{\star \star}$ & 1 & & & & & & & & & & & & & & & & & & & \\
\hline (3) $\mathrm{CO}^{1}$ & $0.76^{\star \star}$ & $0.50^{\star \star}$ & 1 & & & & & & & & & & & & & & & & & & \\
\hline (4) $\mathrm{RO}^{1}$ & $0.76^{\star \star}$ & 0.02 & $0.38^{\star \star}$ & 1 & & & & & & & & & & & & & & & & & \\
\hline (5) $A R^{1}$ & $0.81^{\star \star}$ & $0.27^{\star \star}$ & $0.60^{\star *}$ & $0.54^{\star \star}$ & 1 & & & & & & & & & & & & & & & & \\
\hline (6) $\mathrm{Al}^{1}$ & $0.58^{\star \star}$ & $-0.20^{\star *}$ & $0.20^{\star \star}$ & $0.65^{\star \star}$ & $0.45^{\star \star}$ & 1 & & & & & & & & & & & & & & & \\
\hline (7) $\mathrm{BC}^{1}$ & $0.65^{\star \star}$ & 0.02 & $0.28^{\star \star}$ & $0.62^{\star \star}$ & $0.46^{\star \star}$ & $0.46^{\star \star}$ & 1 & & & & & & & & & & & & & & \\
\hline (8) $\mathrm{GF}^{1}$ & $0.89^{\star \star}$ & $0.53^{\star \star}$ & $0.69^{\star \star}$ & $0.52^{\star \star}$ & $0.71^{\star \star}$ & $0.39^{\star \star}$ & $0.42^{\star \star}$ & 1 & & & & & & & & & & & & & \\
\hline (9) FAST & $0.30^{\star *}$ & $0.29^{\star \star}$ & $0.29^{\star \star}$ & $0.15^{\star}$ & $0.22^{* *}$ & 0.09 & $0.13^{*}$ & $0.30^{\star *}$ & 1 & & & & & & & & & & & & \\
\hline (10) $A U^{2}$ & $0.20^{\star \star}$ & $0.20^{\star \star}$ & $0.18^{\star}$ & $0.13^{*}$ & 0.08 & 0.06 & 0.09 & $0.22^{\star \star}$ & $0.77^{\star \star}$ & 1 & & & & & & & & & & & \\
\hline (11) $\mathrm{OF}^{2}$ & $0.16^{\star}$ & $0.19^{\star \star}$ & 0.11 & $0.13^{\star}$ & 0.04 & 0.04 & $0.13^{*}$ & 0.21 & $0.82^{\star \star}$ & $0.61^{\star \star}$ & 1 & & & & & & & & & & \\
\hline (12) $\mathrm{CF}^{2}$ & $0.24^{\star \star}$ & $0.24^{\star \star}$ & $0.25^{\star \star}$ & 0.06 & $0.20^{\star \star}$ & 0.11 & 0.12 & $0.24^{\star \star}$ & $0.81^{\star \star}$ & $0.53^{\star \star}$ & $0.52^{\star \star}$ & 1 & & & & & & & & & \\
\hline (13) $\mathrm{Fl}^{2}$ & $0.24^{\star \star}$ & $0.18^{\star \star}$ & $0.26^{\star *}$ & $0.14^{\star}$ & $0.21^{\star *}$ & 0.09 & 0.03 & $0.24^{* *}$ & $0.61^{* \star}$ & $0.43^{\star *}$ & $0.39^{\star \star}$ & $0.43^{\star \star}$ & 1 & & & & & & & & \\
\hline (14) $\mathbb{I R}^{2}$ & $0.35^{\star \star}$ & $0.29^{\star \star}$ & $0.34^{\star \star}$ & $0.16^{\star}$ & $0.31^{\star *}$ & 0.11 & 0.09 & $0.37^{\star \star}$ & $0.82^{\star \star}$ & $0.53^{\star \star}$ & $0.52^{\star \star}$ & $0.56^{\star \star}$ & $0.48^{\star \star}$ & 1 & & & & & & & \\
\hline (15) $\mathrm{LT}^{2}$ & $0.21^{\star \star}$ & $0.28^{\star \star}$ & $0.23^{\star \star}$ & 0.04 & $0.18^{\star \star}$ & -0.03 & 0.11 & $0.20^{\star \star}$ & $0.69^{\star \star}$ & $0.45^{\star \star}$ & $0.45^{\star *}$ & $0.61^{\star *}$ & $0.25^{\star \star}$ & $0.57^{\star \star}$ & 1 & & & & & & \\
\hline (16) SSRS & $-0.42^{* \star}$ & $-0.18^{* *}$ & $-0.34^{* *}$ & $-0.30^{\star \star}$ & $-0.40^{\star *}$ & $-0.24^{\star \star}$ & $-0.25^{\star \star}$ & $-0.36^{\star \star}$ & $-0.30^{* *}$ & $-0.21^{\star *}$ & $-0.15^{\star}$ & $-0.27^{\star \star}$ & $-0.13^{*}$ & $-0.35^{\star \star}$ & $-0.29^{\star \star}$ & 1 & & & & & \\
\hline (17) $\mathrm{OS}^{3}$ & $-0.21^{\star *}$ & -0.11 & -0.12 & $-0.17^{\star \star}$ & $-0.22^{\star \star}$ & -0.10 & $-0.18^{\star *}$ & $-0.15^{\star}$ & $-0.15^{\star}$ & -0.08 & -0.08 & -0.15 & 0.02 & $-0.16^{\star}$ & $-0.20^{\star \star}$ & $0.69^{\star \star}$ & 1 & & & & \\
\hline (18) $\mathrm{SS}^{3}$ & $-0.38^{\star *}$ & $-0.16^{\star}$ & $-0.33^{\star \star}$ & $-0.27^{\star \star}$ & $-0.37^{\star \star}$ & $-0.20^{\star *}$ & $-0.20^{\star *}$ & $-0.34^{\star \star}$ & $-0.28^{\star \star}$ & $-0.22^{\star \star}$ & $-015^{\star}$ & $-0.21^{\star \star}$ & $-0.17^{\star \star}$ & $-0.32^{\star \star}$ & $-0.23^{\star \star}$ & $0.88^{\star \star}$ & $0.36^{\star \star}$ & 1 & & & \\
\hline (19) $S U^{3}$ & $-0.32^{* *}$ & -0.10 & $-0.29^{\star \star}$ & $-0.23^{\star *}$ & $-0.26^{\star \star}$ & $-0.25^{\star \star}$ & $-0.16^{\star}$ & $-0.27^{\star \star}$ & $-0.23^{\star \star}$ & -0.12 & -0.10 & $-0.24^{\star \star}$ & $-0.14^{\star}$ & $-0.26^{\star \star}$ & $-0.22^{\star \star}$ & $0.53^{\star \star}$ & 0.12 & $0.33^{\star \star}$ & 1 & & \\
\hline (20) CD-RISC & $-0.33^{\star \star}$ & $-0.23^{* *}$ & $-0.33^{\star \star}$ & $-0.17^{\star}$ & $-0.27^{\star \star}$ & -0.12 & $-0.21^{* *}$ & $-0.28^{\star *}$ & $-0.46^{\star *}$ & $-0.31^{\star *}$ & $-0.33^{\star \star}$ & $-0.36^{\star \star}$ & $-0.22^{\star \star}$ & $-0.43^{\star *}$ & $-0.41^{\star *}$ & $0.38^{\star \star}$ & $0.16^{\star}$ & $0.35^{\star \star}$ & $0.33^{\star \star}$ & 1 & \\
\hline (21) BSI & $-0.15^{*}$ & $-0.15^{*}$ & $-0.16^{*}$ & 0.01 & $-0.13^{*}$ & -0.04 & -0.10 & $-0.17^{* *}$ & $-0.27^{\star \star}$ & $-0.18^{\star *}$ & $-0.18^{\star \star}$ & $-0.29^{\star \star}$ & $-0.15^{*}$ & $-0.20^{* *}$ & $-0.23^{\star \star}$ & $0.15^{\star}$ & 0.03 & $0.17^{\star \star}$ & 0.10 & $0.21^{\star \star}$ & 1 \\
\hline
\end{tabular}

FAD, Family Assessment Device; FAST, Functioning Assessment Short Test; SSRS, Social Support Rating Scale; CD-RISC, Connor-Davidson Resilience Scale; BSI, Beck Scale for Suicide Ideation; PS, Problem Solving; CO, Communication; RO, Roles; AR, Affective Responsiveness; Al, Affective Involvement; BC, Behavior Control; GF, General Functioning; AU, Autonomy; OF, Occupational Functioning; CF, Cognitive Functioning; Fl, Financial Issue; IR, Interpersonal Relationships; LT, Leisure Time; OS, Objective Support; SS, Subjective Support; SU, Support Utilization.

1 family functioning; ${ }^{2}$ psychosocial functioning: ${ }^{3}$ social support.

\#The 17-item Hamilton Depression Rating Scale and Young Mania Rating Scale scores were controlled as covariant variables.

${ }^{*} p<0.05,{ }^{* *} p<0.01$ 
TABLE 4 | Results of predicting effects of family functioning, social support, suicidal ideation, and resilience on psychosocial functioning.

\begin{tabular}{|c|c|c|c|c|c|c|c|c|c|c|c|c|c|c|}
\hline \multirow[t]{2}{*}{ Variables } & \multicolumn{2}{|c|}{$\begin{array}{c}\text { Total score of } \\
\text { FAST }\end{array}$} & \multicolumn{2}{|c|}{ Autonomy } & \multicolumn{2}{|c|}{$\begin{array}{l}\text { Occupational } \\
\text { functioning }\end{array}$} & \multicolumn{2}{|c|}{$\begin{array}{l}\text { Cognitive } \\
\text { functioning }\end{array}$} & \multicolumn{2}{|c|}{$\begin{array}{l}\text { Financial } \\
\text { issue }\end{array}$} & \multicolumn{2}{|c|}{$\begin{array}{l}\text { Interpersonal } \\
\text { relationships }\end{array}$} & \multicolumn{2}{|c|}{ Leisure time } \\
\hline & $\beta$ & $p$ & $\beta$ & $p$ & $\beta$ & $p$ & $\beta$ & $p$ & $\beta$ & $p$ & $\beta$ & $p$ & $\beta$ & $p$ \\
\hline HDRS-17 & 0.216 & $0.001^{\star \star}$ & 0.132 & 0.085 & 0.068 & 0.370 & 0.198 & $0.005^{\star \star}$ & 0.201 & $0.009^{\star \star}$ & 0.268 & $<0.001^{\star \star}$ & 0.050 & 0.498 \\
\hline YMRS & 0.025 & 0.701 & 0.044 & 0.559 & 0.024 & 0.750 & 0.067 & 0.338 & 0.023 & 0.759 & 0.018 & 0.777 & -0.034 & 0.638 \\
\hline Age & - & - & - & - & -0.199 & $0.003^{\star \star}$ & - & - & - & - & - & - & - & - \\
\hline Gender & - & - & - & - & - & - & - & - & -0.163 & $0.012^{\star}$ & - & - & - & - \\
\hline The FAD & 0.139 & $0.021^{\star}$ & - & - & - & - & - & - & 0.158 & $0.022^{\star}$ & 0.142 & $0.023^{\star}$ & - & - \\
\hline The SSRS & - & - & - & - & - & - & - & - & - & - & -0.197 & $0.003^{\star \star}$ & -0.154 & $0.029^{\star}$ \\
\hline The CD-RISC & -0.393 & $<0.001^{\star \star}$ & -0.343 & $<0.001^{\star \star}$ & -0.297 & $<0.001^{\star \star}$ & -0.318 & $<0.001^{\star \star}$ & -0.171 & $0.014^{\star}$ & -0.301 & $<0.001^{\star \star}$ & -0.350 & $<0.001^{\star \star}$ \\
\hline The BSI & -0.131 & $0.034^{*}$ & - & - & -0.174 & $0.013^{\star}$ & -0.220 & $0.001^{\star \star}$ & - & - & - & - & -0139 & $0.030^{*}$ \\
\hline \multicolumn{15}{|c|}{ Goodness of fit of the model } \\
\hline$R^{2}$ & \multicolumn{2}{|c|}{0.367} & \multicolumn{2}{|c|}{0.154} & \multicolumn{2}{|c|}{0.171} & \multicolumn{2}{|c|}{0.277} & \multicolumn{2}{|c|}{0.156} & \multicolumn{2}{|c|}{0.401} & \multicolumn{2}{|c|}{0.232} \\
\hline $\mathrm{F}$ & \multicolumn{2}{|c|}{$0.034^{\star}$} & \multicolumn{2}{|c|}{$<0.001^{\star \star}$} & \multicolumn{2}{|c|}{$0.013^{*}$} & \multicolumn{2}{|c|}{$<0.001^{\star \star}$} & \multicolumn{2}{|c|}{$0.022^{\star}$} & \multicolumn{2}{|c|}{$0.023^{\star}$} & \multicolumn{2}{|c|}{$0.030^{\star}$} \\
\hline$p$ & \multicolumn{2}{|c|}{20.701} & \multicolumn{2}{|c|}{13.353} & \multicolumn{2}{|c|}{9.394} & \multicolumn{2}{|c|}{20.526} & \multicolumn{2}{|c|}{8.569} & \multicolumn{2}{|c|}{23.793} & \multicolumn{2}{|c|}{13.335} \\
\hline VIF ${ }^{8}$ (highest) & \multicolumn{2}{|c|}{1.398} & \multicolumn{2}{|c|}{1.048} & \multicolumn{2}{|c|}{1.180} & \multicolumn{2}{|c|}{1.394} & 1.3 & 393 & & 476 & & 294 \\
\hline Tolerance (lowest) & & 716 & $0 . \subseteq$ & 954 & & 848 & 0.7 & 717 & 0.7 & 18 & & 677 & & 773 \\
\hline
\end{tabular}

FAST, Functioning Assessment Short Test; HDRS-17, the 17-item Hamilton Depression Rating Scale; YMRS, Young Mania Rating Scale; FAD, Family Assessment Device; SSRS, Social Support Rating Scale; CD-RISC, Connor-Davidson Resilience Scale; BSI, Beck Scale for Suicide Ideation; VIF, variance inflation factor. ${ }^{*} p<0.05,{ }^{* *} p<0.01$.

TABLE 5 | Standardized direct, indirect and total effects of family functioning on psychosocial functioning

\begin{tabular}{|c|c|c|c|c|c|c|c|c|c|}
\hline \multirow[t]{2}{*}{ Exogenous variables } & \multirow[t]{2}{*}{ Endogenous variables } & \multicolumn{2}{|c|}{ Standardized path coefficient } & \multirow[t]{2}{*}{ C.R. } & \multirow[t]{2}{*}{$S E$} & \multirow[t]{2}{*}{$S D E$} & \multirow[t]{2}{*}{ SIE } & \multirow[t]{2}{*}{ STE } & \multirow[t]{2}{*}{ SMC } \\
\hline & & $\beta$ & $95 \% \mathrm{Cl}$ & & & & & & \\
\hline Family functioning & Social support & -0.454 & {$[-0.607,-0.305]$} & $-4.602^{\star \star}$ & 0.037 & $-0.454^{\star \star}$ & $-0.150^{\star \star}$ & $-0.604^{\star \star}$ & 0.483 \\
\hline Resilience & & 0.375 & {$[0.209,0.523]$} & $4.214^{\star \star}$ & 0.007 & $0.375^{\star \star}$ & & $0.375^{\star \star}$ & \\
\hline Family functioning & Resilience & -0.359 & {$[-0.461,-0.246]$} & $-5.710^{\star *}$ & 0.296 & $-0.359^{\star \star}$ & $-0.042^{\star \star}$ & $-0.400^{\star \star}$ & 0.190 \\
\hline Suicidal ideation & & 0.177 & {$[0.054,0.290]$} & $2.961^{\star \star}$ & 0.249 & $0.177^{\star \star}$ & & $0.177^{\star \star}$ & \\
\hline Family functioning & Suicidal ideation & -0.236 & {$[-0.360,-0.111]$} & $-3.641^{\star \star}$ & 0.073 & $-0.236^{\star \star}$ & & $-0.236^{\star \star}$ & 0.056 \\
\hline Family functioning & Psychosocial functioning & 0.137 & {$[-0.059,0.316]$} & 1.653 & 0.028 & 0.137 & $0.320^{\star *}$ & $0.457^{\star \star}$ & 0.438 \\
\hline Social support & & -0.250 & {$[-0.566,-0.036]$} & $-2.136^{\star}$ & 0.106 & $-0.250^{\star}$ & & $-0.250^{\star}$ & \\
\hline Resilience & & -0.314 & {$[-0.463,-0.119]$} & $-4.094^{\star \star}$ & 0.006 & $-0.314^{\star \star}$ & $-0.094^{*}$ & $-0.408^{\star \star}$ & \\
\hline Suicidal ideation & & -0.185 & {$[-0.283,-0.081]$} & $-3.206^{\star \star}$ & 0.017 & $-0.185^{\star \star}$ & $-0.072^{\star \star}$ & $-0.257^{\star \star}$ & \\
\hline
\end{tabular}

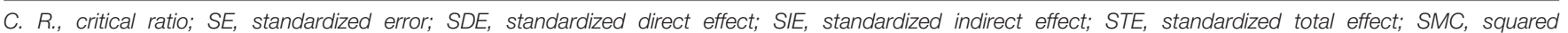
multiple correlation.

${ }^{*} p<0.05,{ }^{* *} p<0.01$.

treatments, such as Family-focused treatment (FFT), Child- and family-focused cognitive behavior therapy (RAINBOW) and Multi-family psychoeducational groups (MFPG), combined with pharmacotherapy in patients with $\mathrm{BD}$, are demonstrated to make significant effects on improving clinical symptoms, reducing family aggression and gaining in social support (Pavuluri et al., 2004; Carr, 2009; Fristad et al., 2015; Miklowitz and Chung, 2016). Furthermore, the systemic family therapy also could make significant improvements in psychosocial functioning through the potential effectiveness of family functioning (Carr, 2009). In future studies, comprehensive assessment (e.g., Behavioral control, affective responsiveness, affective involvement, and roles) and competency training should be provided to their families. Psychosocial functioning (all dimensions) in bipolar patients was worse than that in healthy, which is in line with other and our previous studies (Sanchez-Moreno et al., 2017;
Lin et al., 2020). Clinical factors, including past psychotic history, the number of hospitalizations, comorbidities and episodes of depression, have been demonstrated to be related to psychosocial functioning in previous studies (Sanchez-Moreno et al., 2017). Therefore, it is essential to implement psychosocial interventions for patients with $\mathrm{BD}$.

Family functioning could significantly predict global and six domain-specific psychosocial functioning in patients with $\mathrm{BD}$, suggesting that family has an influence on deficient psychosocial functioning. As suggested in Miklowitz and Chung (2016) and Sullivan et al. (2012), mood symptoms might affect the family environment and psychosocial functioning. There was no significant change in the results after controlling for the HDRS-17 and YMRS scores. This finding was enriched in the study by MacPherson et al. (2018), which documented that family dysfunction exists even when patients with $\mathrm{BD}$ are in 
remission. A prior study explored the significant association between family burden and psychosocial functioning in firstepisode and chronic psychosis, again supporting the idea that family functioning is related to psychosocial functioning in general rather than in $\mathrm{BD}$ specifically (Koutra et al., 2016). Thus, evidence-based psychosocial treatments (EBTs) and psychoeducational interventions for patients with $\mathrm{BD}$ combined with family strategies improve functioning and better promote the recovery of patients (Fristad and MacPherson, 2014).

Patients with BD reported less social support than the general population, especially subjective support, which is consistent with the article by Lei and Kantor (2021). A previous study illustrated that subjective support was correlated with the behavior and development of patients as a psychological perception of reality (Lu et al., 2021). The assessment of the patient's satisfaction with being respected, understood, and supported in society is necessary when intervening in the social support of patients with bipolar disorder (Lei and Kantor, 2021). Although the measurements are inconsistent, the findings are consistent previous studies (Guerrero-Jimenez et al., 2021; Lei and Kantor, 2021) suggesting that social support is related to family functioning and psychosocial functioning. The absence of social support, especially through their families of origin (parents and/or primary caregiver), can trigger clinical symptoms (Owen et al., 2017; MacPherson et al., 2018). Hypomania results in the establishment of new social relationships, whereas exacerbated affective symptoms can break intimate connections (Owen et al., 2017), creating a vicious cycle. In the present research, social support mediates the relationship between family and psychosocial functioning, and it is further well documented that social support of patients can enhance the impact of family functioning in promoting patient recovery. Therefore, it is important to develop a targeted support service in objective and subjective social support to strengthen family functioning and facilitate psychosocial functioning recovery in patients with BD.

As expected, the association between family and psychosocial functioning could be predicted and mediated by resilience in BD patients. Consistent with previous studies, resilience is an essential factor affecting family functioning and psychosocial functioning (Walsh, 2003; Kim et al., 2013). The relationship between resilience and family resilience is bidirectional. Family resilience, which is a component of the developmental perspective of family functioning, extends the understanding of family functioning in adversity (Walsh, 2015). Resilience can improve the quality of life and well-being of patients and their family members by actively contributing to the construction of well-functioning families (Kukihara et al., 2020; Wang et al., 2021). The explanation of mediatory role resilience is well family adaptability, and effective communication results in greater resilience, which is associated with better mental well-being (Kukihara et al., 2020). Notably, the assessment and intervention of family functioning of patients should emphasize the reconstruction of their resilience in coping with the diversity and complexity of family processes (Walsh, 2003, 2015). Another finding that cannot be ignored is that resilience negatively predicts psychosocial functioning directly and indirectly through the positive effect of social support. Resilience and social support as protective factors have been found to reduce the occurrence of abuse-related behaviors in patients with dementia (Lídia et al., 2018). The mediating role of social support between resilience and quality of life was explored in breast cancer patients (Zhang et al., 2017). Our findings contribute to the mediating roles of resilience, social support and psychosocial functioning on family functioning in patients with bipolar disorder. Therefore, family strategies should be formulated to improve psychosocial functioning of patients, and emphasis should be placed on enhancing resilience while strengthening social support.

Interestingly, suicidal ideation was negatively associated with family functioning, and this relationship was also found in suicidal ideation and psychosocial functioning. Nevertheless, in contrast to our present study, previous studies indicated that a worse family environment predicted higher suicidal ideation or suicide attempts (Goldstein et al., 2009; Berutti et al., 2016). Goldstein et al. (2009) combined the Conflict Behavior Questionnaire (CBQ), FACES-II, and the Life Events Checklist $(L E C)$ to measure the family environment in 446 bipolar youth patients, and the total sample in the study of Berutti et al. (2016) was relatively small (62 participants). Another explanation for this distinction is that the best family relationship is formed by taking the best possible care of families in Chinese households. This may cause an increase in the sense of hopelessness, which consequently enhances suicidal ideation (Kwok and Shek, 2010). Notably, suicidal ideation plays a mediatory role between family and psychosocial functioning in BD patients. The families of suicidal patients were characterized by higher divorce and separation and lower cohesion and adaptability, which led to psychosocial dysfunction (Goldstein et al., 2009). Suicidal ideation as a predictor of compromised functioning has long been established, and early identification and continuous intervention are required, especially in family and psychosocial functioning (Reinherz et al., 2006; Berutti et al., 2016).

\section{LIMITATION AND STRENGTHS}

Several limitations should be acknowledged in the study. First, the assessment of family functioning was only determined from data collected via patients' self-reports and did not include reports from intimate relatives. Parents, offspring and spouses in $\mathrm{BD}$ families, which play indivisible roles in the daily life of patients with $\mathrm{BD}$, often demonstrate a lack of consistent reporting in family functioning (Shalev et al., 2019). Thus, further studies of families of patients with $\mathrm{BD}$ should be rated to provide a comprehensive assessment of their living status and family members. Second, although medication was described at baseline, we cannot exclude the effects of pharmacotherapy on changes in these variables. For instance, benzodiazepine could cause sedation and affect the assessment of neurocognitive performance and psychosocial functioning (Baandrup et al., 2017). Third, the research design is cross-sectional, and causal inferences between family functioning and psychosocial functioning cannot be made. Additionally, suicidal ideation is the long-term outcome of multiple factors, and recent suicidal ideation or the 
number of attempted suicides does not correlate with worse family functioning (Berutti et al., 2016). Therefore, longitudinal assessments should ideally be conducted, which could explore variations in the relationship among family functioning, suicidal ideation and psychosocial functioning with the timeline. To the best of our knowledge, this is the first study to investigate the mediating role of social support, resilience and suicidal ideation in family functioning and psychosocial functioning in BD patients. Furthermore, our sample is better characterized by related clinical features, and the sample size is relatively large, which has yielded better results in prior studies.

\section{CONCLUSION}

The present study notes significant family and psychosocial dysfunction, reduced social support and resilience, and a higher level of suicidal ideation in bipolar patients compared with healthy individuals. Associations were found among family functioning, psychosocial functioning, social support, resilience and suicidal ideation in bipolar patients. Social support, resilience and suicidal ideation could indirectly mediate the effect of family functioning on psychosocial functioning in bipolar patients. These findings suggest that clinical or community interventions for bipolar patients should be combined with family strategies and emphasize enhancing social support and resilience while paying attention to patients' suicidal ideation, which might improve psychosocial functioning.

\section{REFERENCES}

Abreu, L. N., Lafer, B., Baca-Garcia, E., and Oquendo, M. A. (2009). Suicidal ideation and suicide attempts in bipolar disorder type I: an update for the clinician. Braz. J. Psychiatry 31, 271-280. doi: 10.1590/s151644462009005000003

Baandrup, L., Fagerlund, B., and Glenthoj, B. (2017). Neurocognitive performance, subjective well-being, and psychosocial functioning after benzodiazepine withdrawal in patients with schizophrenia or bipolar disorder: a randomized clinical trial of add-on melatonin versus placebo. Eur. Arch. Psychiatry Clin. Neurosci. 267, 163-171. doi: 10.1007/s00406-016-0711-8

Beck, A. T., Kovacs, M., and Weissman, A. (1979). Assessment of suicidal intention: the scale for suicide ideation. J. Consult. Clin. Psychol. 47, 343-352. doi: 10.1037/ /0022-006x.47.2.343

Berutti, M., Dias, R. S., Pereira, V. A., Lafer, B., and Nery, F. G. (2016). Association between history of suicide attempts and family functioning in bipolar disorder. J. Affect. Disord. 192, 28-33. doi: 10.1016/j.jad.2015.12.010

Bonnin, C. M., Torrent, C., Arango, C., Amann, B. L., Sole, B., Gonzalez-Pinto, A., et al. (2016). Functional remediation in bipolar disorder: 1-Year followup of neurocognitive and functional outcome. Br. J. Psychiatry 208, 87-93. doi: 10.1192/bjp.bp.114.162123

Carr, A. (2009). Bipolar disorder in young people: description, assessment and evidence-based treatment. Dev. Neurorehabil. 12, 427-441. doi: 10.3109/ 17518420903042454

Carvalho, A. F., Firth, J., and Vieta, E. (2020). Bipolar disorder. N. Engl. J. Med. 383, 58-66. doi: 10.1056/NEJMra1906193

Chang, K. D., Blasey, C., Ketter, T. A., and Steiner, H. (2001). Family environment of children and adolescents with bipolar parents. Bipolar. Disord. 3, 73-78. doi: 10.1034/j.1399-5618.2001.030205.x

Cicchetti, D. (2010). Resilience under conditions of extreme stress: a multilevel perspective. World Psychiatry 9, 145-154. doi: 10.1002/j.2051-5545.2010. tb00297.x

\section{DATA AVAILABILITY STATEMENT}

The raw data supporting the conclusions of this article will be made available by the authors, without undue reservation.

\section{ETHICS STATEMENT}

The studies involving human participants were reviewed and approved by L2019ZSLYEC-021, Sun Yat-sen University. The patients/participants provided their written informed consent to participate in this study.

\section{AUTHOR CONTRIBUTIONS}

XL designed the study and wrote the protocol. WD and XL undertook the statistical analysis and wrote the first draft of the manuscript. XL, DL, and YZ revised the manuscript. XY, HF, LC, YZ, KZ, and DL managed the data collection and clinical evaluations. All authors contributed to and have approved the final manuscript.

\section{FUNDING}

This work was supported by the National Natural Science Foundation of China (Grant Number 71904213).

Connor, K. M., and Davidson, J. R. (2003). Development of a new resilience scale: the connor-davidson resilience scale (CD-RISC). Depress. Anxiety. 18, 76-82. doi: 10.1002/da.10113

Du Rocher, S. T., Youngstrom, E. A., Calabrese, J. R., and Findling, R. L. (2008). The role of family functioning in bipolar disorder in families. J. Abnorm. Child Psychol. 36, 849-863. doi: 10.1007/s10802-008-9217-9

Dunne, L., Perich, T., and Meade, T. (2019). The relationship between social support and personal recovery in bipolar disorder. Psychiatr. Rehabil. J. 42, 100-103. doi: 10.1037/pri0000319

Epstein, N. B., Baldwin, L. M., and Bishop, D. S. (1983). The McMaster family assessment device. J. Mar. Fam. Ther. 9, 171-180.

Fristad, M. A., and MacPherson, H. A. (2014). Evidence-based psychosocial treatments for child and adolescent bipolar spectrum disorders. J. Clin. Child Adolesc. Psychol. 43, 339-355. doi: 10.1080/15374416.2013.82 2309

Fristad, M. A., Ronald, J. G., and Gavazzi, S. M. (2015). Multifamily psychoeducation groups (MFPG) for families of children with bipolar disorder. Bipolar. Disord. 4:9073. doi: 10.1034/j.1399-5618.2002.0 9073. $\mathrm{x}$

Goldstein, T. R., Birmaher, B., Axelson, D., Goldstein, B. I., Gill, M. K., EspositoSmythers, C., et al. (2009). Family environment and suicidal ideation among bipolar youth. Arch. Suicide Res. 13, 378-388. doi: 10.1080/1381111090326 6699

Guerrero-Jimenez, M., Gutierrez, B., and Cervilla, J. A. (2021). Psychotic symptoms associate inversely with social support, social autonomy and psychosocial functioning: a community-based study. Int. J. Soc. Psychiatry 21:17086078. doi: $10.1177 / 00207640211011198$

Hamilton, M. (1960). A rating scale for depression. J. Neurol. Neurosurg. Psychiatry 23, 56-62. doi: 10.1136/jnnp.23.1.56

Karow, A., Moritz, S., Lambert, M., Schottle, D., and Naber, D. (2012). Remitted but still impaired? Symptomatic versus functional remission in patients with schizophrenia. Eur. Psychiatry 27, 401-405. doi: 10.1016/j.eurpsy.2011.01.012 
Keenan-Miller, D., Peris, T., Axelson, D., Kowatch, R. A., and Miklowitz, D. J. (2012). Family functioning, social impairment, and symptoms among adolescents with bipolar disorder. J. Am. Acad. Child Adolesc. Psychiatry 51, 1085-1094. doi: 10.1016/j.jaac.2012.08.005

Kim, K. R., Song, Y. Y., Park, J. Y., Lee, E. H., Lee, M., and Lee, S. Y. (2013). The relationship between psychosocial functioning and resilience and negative symptoms in individuals at ultra-high risk for psychosis. Aust. N. Z. J. Psychiatry 47, 762-771. doi: 10.1177/0004867413488218

Koutra, K., Triliva, S., Roumeliotaki, T., Basta, M., Lionis, C., and Vgontzas, A. N. (2016). Family functioning in First-Episode and chronic psychosis: the role of patient's symptom severity and psychosocial functioning. Commun. Ment. Health J. 52, 710-723. doi: 10.1007/s10597-015-9916-y

Kukihara, H., Yamawaki, N., Ando, M., Nishio, M., Kimura, H., and Tamura, Y. (2020). The mediating effect of resilience between family functioning and mental well-being in hemodialysis patients in Japan: a cross-sectional design. Health Qual. Life Outcomes 18:233. doi: 10.1186/s12955-020-01 486-X

Kwok, S. Y., and Shek, D. T. (2010). Hopelessness, parent-adolescent communication, and suicidal ideation among Chinese adolescents in Hong Kong. Suicide Life Threat. Behav. 40, 224-233. doi: 10.1521/suli. 2010.40.3.224

Lee, D., Cha, B., Park, C. S., Kim, B. J., Lee, C. S., Lee, S. J., et al. (2017). Effects of resilience on quality of life in patients with bipolar disorder. J. Affect. Disord. 207, 434-441. doi: 10.1016/j.jad.2016.08.075

Lei, X., and Kantor, J. (2021). Social support and family functioning in Chinese families of children with autism spectrum disorder. Int. J. Environ. Res. Public Health 18:3504. doi: 10.3390/ijerph18073504

Lídia, S., Israel, C., Bernardino, F. C., Pablo, R., Cristina, J., Noelia, F., et al. (2018). Resilience and social support as protective factors against abuse of patients with dementia: a study on family caregivers. Int. J. Geriatr. Psych. 33, 1132-1138.

Lin, X., Lu, D., Zhu, Y., Luo, X., Huang, Z., and Chen, W. (2020). The effects of cognitive reserve on predicting and moderating the cognitive and psychosocial functioning of patients with bipolar disorder. J. Affect. Disord. 260, 222-231. doi: 10.1016/j.jad.2019.09.019

Lu, M., Chen, J., He, W., Pang, F., and Zou, Y. (2021). Association between perceived social support of parents and emotional/behavioral problems in children with ASD: A chain mediation model. Res. Dev. Disabil. 113:103933. doi: $10.1016 /$ j.ridd.2021.103933

Luo, X., Zhu, Y., Lu, D., Zong, K., and Lin, X. (2020). Subjective cognitive dysfunction in patients with bipolar disorder: the prevalence, related factors and effects on predicting psychosocial functioning and suicidal ideation. Psychiatry Res. 284:112669. doi: 10.1016/j.psychres.2019.112669

MacPherson, H. A., Ruggieri, A. L., Christensen, R. E., Schettini, E., Kim, K. L., Thomas, S. A., et al. (2018). Developmental evaluation of family functioning deficits in youths and young adults with childhood-onset bipolar disorder. J. Affect. Disord. 235, 574-582. doi: 10.1016/j.jad.2018.04.078

McDonald, R. P., and Ho, M. H. (2002). Principles and practice in reporting structural equation analyses. Psychol. Methods 7, 64-82. doi: 10.1037/1082989x.7.1.64

Miklowitz, D. J., and Chung, B. (2016). Family-focused therapy for bipolar disorder: reflections on 30 years of research. Fam. Process. 55, 483-499. doi: 10.1111/famp.12237

Mizuno, Y., Hofer, A., Suzuki, T., Frajo-Apor, B., Wartelsteiner, F., Kemmler, G., et al. (2016). Clinical and biological correlates of resilience in patients with schizophrenia and bipolar disorder: a cross-sectional study. Schizophr. Res. 175, 148-153. doi: 10.1016/j.schres.2016.04.047

O’Donnell, L. A., Weintraub, M. J., Ellis, A. J., Axelson, D. A., Kowatch, R. A., Schneck, C. D., et al. (2020). A randomized comparison of two psychosocial interventions on family functioning in adolescents with bipolar disorder. Fam. Process. 59, 376-389. doi: 10.1111/famp.12521

Owen, R., Gooding, P., Dempsey, R., and Jones, S. (2017). The reciprocal relationship between bipolar disorder and social interaction: a qualitative investigation. Clin. Psychol. Psychother. 24, 911-918. doi: 10.1002/cpp. 2055

Pavuluri, M. N., Patricia, A. G. P. D., David, B. H. P. D., Carbray, J. A., Jodi, H. L. C. S., and David, J. M. P. D. (2004). Child- and family-focused cognitivebehavioral therapy for pediatric bipolar disorder: development and preliminary results. J. Am. Acad. Child Adoles. Psychiatry 43, 528-537. doi: 10.1097/ 00004583-200405000-00006

Perlis, R. H., Dennehy, E. B., Miklowitz, D. J., Delbello, M. P., Ostacher, M., Calabrese, J. R., et al. (2009). Retrospective age at onset of bipolar disorder and outcome during two-year follow-up: Results from the STEP-BD study. Bipolar. Disord. 11, 391-400. doi: 10.1111/j.1399-5618.2009.00686.x

Pompili, M., Gonda, X., Serafini, G., Innamorati, M., Sher, L., Amore, M., et al. (2013). Epidemiology of suicide in bipolar disorders: a systematic review of the literature. Bipolar. Disord. 15, 457-490. doi: 10.1111/bdi.1 2087

Reinherz, H. Z., Tanner, J. L., Berger, S. R., Beardslee, W. R., and Fitzmaurice, G. M. (2006). Adolescent suicidal ideation as predictive of psychopathology, suicidal behavior, and compromised functioning at age 30. Am. J. Psychiatry 163, 1226-1232. doi: 10.1176/appi.ajp.163.7.1226

Sanchez-Moreno, J., Martinez-Aran, A., and Vieta, E. (2017). Treatment of functional impairment in patients with bipolar disorder. Curr. Psychiatry Rep. 19:3. doi: 10.1007/s11920-017-0752-3

Shalev, A., Merranko, J., Goldstein, T., Miklowitz, D. J., Axelson, D., Goldstein, B. I., et al. (2019). A longitudinal study of family functioning in offspring of parents diagnosed with bipolar disorder. J. Am. Acad. Child Adolesc. Psychiatry 58, 961-970. doi: 10.1016/j.jaac.2018.10.011

Sole, B., Bonnin, C. M., Jimenez, E., Torrent, C., Torres, I., Varo, C., et al. (2018). Heterogeneity of functional outcomes in patients with bipolar disorder: A cluster-analytic approach. Acta Psychiatr. Scand. 137, 516-527. doi: 10.1111/ acps. 12871

Sperry, D. M., and Widom, C. S. (2013). Child abuse and neglect, social support, and psychopathology in adulthood: A prospective investigation. Child Abuse Negl. 37, 415-425. doi: 10.1016/j.chiabu.2013.02.006

Stapp, E. K., Musci, R. J., Fullerton, J. M., Glowinski, A. L., McInnis, M., Mitchell, P. B., et al. (2019). Patterns and predictors of family environment among adolescents at high and low risk for familial bipolar disorder. J. Psychiatr. Res. 114, 153-160. doi: 10.1016/j.jpsychires.2019.05.003

Steinhausen, H. C., and Metzke, C. W. (2004). The impact of suicidal ideation in preadolescence, adolescence, and young adulthood on psychosocial functioning and psychopathology in young adulthood. Acta Psychiatr. Scand. 110, 438-445. doi: 10.1111/j.1600-0447.2004.00364.x

Sullivan, A. E., Judd, C. M., Axelson, D. A., and Miklowitz, D. J. (2012). Family functioning and the course of adolescent bipolar disorder. Behav. Ther. 43, 837-847. doi: 10.1016/j.beth.2012.04.005

Walsh, F. (2003). Family resilience: a framework for clinical practice. Fam. Process. 42, 1-18. doi: 10.1111/j.1545-5300.2003.00001.x

Walsh, F. (2015). Normal Family Processes: Growing Diversity and Complexity. New York, NY: Guilford Press.

Wang, H., Yue, H., Ren, M., and Feng, D. (2021). Dyadic effects of familyfunctioning and resilience on quality of life in advanced lung cancer patients and caregivers: An actor-partner interdependence mediation model. Eur. J. Oncol. Nurs. 52:101963. doi: 10.1016/j.ejon.2021.101963

Wang, J., and Zhao, X. (2012). Family functioning and social support for older patients with depression in an urban area of Shanghai, China. Arch Gerontol Geriatr. 55, 574-579. doi: 10.1016/j.archger.2012.06.011

Wang, Y. H., Haslam, M., Yu, M., Ding, J., Lu, Q., and Pan, F. (2015). Family functioning, marital quality and social support in Chinese patients with epilepsy. Health Qual. Life Outcomes. 13:10. doi: 10.1186/s12955-0150208-6

Weinstein, S. M., Van Meter, A., Katz, A. C., Peters, A. T., and West, A. E. (2015). Cognitive and family correlates of current suicidal ideation in children with bipolar disorder. J. Affect. Disord. 173, 15-21. doi: 10.1016/j.jad.2014. 10.058

West, A. E., and Cosgrove, V. E. (2019). Editorial: the impact of parental psychopathology on family functioning: prioritizing transdiagnostic interventions with parents and families. J. Am. Acad. Child Adolesc. Psychiatry. 58, 940-942. doi: 10.1016/j.jaac.2019.04.005

Xian-Yun, L., Phillips, M. R., Tong, Y. S., Ke-Jin, L. I., Zhang, Y. L., and Zhang, A.-P. (2010). Reliability and validity of the Chinese version of Beck Suicide Ideation Scale (BSI-CV) in adult community residents. Chin. Ment. Health J. 24, 250-255. doi: 10.3969/j.issn.1000-6729.2010.04.003

Yang, C., Zhou, Y., and Xia, M. (2020). How resilience promotes mental health of patients with DSM-5 substance use disorder? The mediation roles of positive 
affect, Self-Esteem, and perceived social support. Front. Psychiatry. 11:588968. doi: $10.3389 /$ fpsyt.2020.588968

Young, R. C., Biggs, J. T., Ziegler, V. E., and Meyer, D. A. (1978). A rating scale for mania: reliability, validity and sensitivity. Br. J. Psychiatry 133, 429-435. doi: 10.1192/bjp.133.5.429

Yu, Y. H., Peng, M. M., Bai, X., Luo, W., Yang, X., Li, J., et al. (2020). Schizophrenia, social support, caregiving burden and household poverty in rural China. Soc. Psychiatry Psychiatr. Epidemiol. 55, 1571-1580. doi: 10.1007/s00127-02001864-2

Zhang, H., Zhao, Q., Cao, P., and Ren, G. (2017). Resilience and quality of life: Exploring the mediator role of social support in patients with breast cancer. Med. Sci. Monit. 23, 5969-5979. doi: 10.12659/msm.907730

Zhang, X., Zhao, M., Li, J., Shi, L., Xu, X., Dai, Q., et al. (2019). Associations between family cohesion, adaptability, and functioning of patients with bipolar disorder with clinical syndromes in Hebei, China. J. Int. Med. Res. 47, 6004-6015. doi: $10.1177 / 0300060519877030$

Zhang, Y., Long, X., Ma, X., He, Q., Luo, X., Bian, Y., et al. (2018). Psychometric properties of the Chinese version of the Functioning assessment short test (FAST) in bipolar disorder. J. Affect. Disord. 238, 156-160. doi: 10.1016/j.jad. 2018.05.019

Zhou, J., Feng, L., Hu, C., Pao, C., Xiao, L., and Wang, G. (2019). Associations among depressive symptoms, childhood abuse, neuroticism, social support, and coping style in the population covering general adults, depressed patients, bipolar disorder patients, and high risk population for depression. Front. Psychol. 10:1321. doi: 10.3389/fpsyg.2019. 01321

Conflict of Interest: The authors declare that the research was conducted in the absence of any commercial or financial relationships that could be construed as a potential conflict of interest.

Publisher's Note: All claims expressed in this article are solely those of the authors and do not necessarily represent those of their affiliated organizations, or those of the publisher, the editors and the reviewers. Any product that may be evaluated in this article, or claim that may be made by its manufacturer, is not guaranteed or endorsed by the publisher.

Copyright (c) 2022 Dou, Yu, Fang, Lu, Cai, Zhu, Zong, Zheng and Lin. This is an open-access article distributed under the terms of the Creative Commons Attribution License (CC BY). The use, distribution or reproduction in other forums is permitted, provided the original author(s) and the copyright owner(s) are credited and that the original publication in this journal is cited, in accordance with accepted academic practice. No use, distribution or reproduction is permitted which does not comply with these terms. 